\title{
Cost of Moderate to Severe Plaque Psoriasis in Germany: A Multicenter Cost-of-IIIness Study
}

\author{
S. Sohn ${ }^{a}$ O. Schoeffski ${ }^{a} \quad$ J. Prinz ${ }^{b} \quad$ K. Reich ${ }^{c} \quad$ E. Schubert ${ }^{d} \quad$ K. Waldorf ${ }^{e}$ \\ M. Augustin ${ }^{f}$
}

${ }^{a}$ Chair for Health Management, University of Erlangen-Nuremberg, Nuremberg; ${ }^{b}$ Department of Dermatology, Ludwig Maximilian University Hospital, Munich; ${ }^{c}$ Department of Dermatology, University Hospital, Göttingen;

${ }^{\mathrm{d}}$ Along with H. Frank, M. Beck-Bohlen, C. Kristen, Würzburg; ${ }^{e}$ Waldorf \& Partner Health Consulting, Hanover, and ${ }^{\mathrm{f}}$ Department of Dermatology, University Hospital, Hamburg, Germany

\section{Key Words}

Moderate to severe plaque psoriasis - Cost of illness .

Psoriasis Area and Severity Index · Psoriatic body

surface area

\begin{abstract}
Background: There is little information concerning the costs of psoriasis and patients' quality of life ( $\mathrm{OoL}$ ) in Germany. Objective: To obtain data on the annual costs and QoL (to follow in a further publication) of patients with moderate to severe plaque psoriasis. Methods: Between October 2003 and February 2004, six office-based dermatologists and eight dermatology outpatient departments retrospectively documented cost-of-illness data from a societal cost perspective in 184 patients over a 12-month period. Patients were stratified into three subgroups according to their treatment scheme. Results: Mean total costs amounted to $€ 6,709$ per patient and year. The mean PASI score was 18.2 and PBSA $28.9 \%$. Annual costs were highest with $€ 8,831$ in high-need patients. They also showed the highest PASI score (22.2). Conclusion: Moderate to severe plaque psoriasis is as-
\end{abstract}

sociated with tremendous costs, particularly in patients not adequately controlled by conventional therapies, while the outcomes of patients were unsatisfactory.

Copyright $(2006$ S. Karger AG, Basel

\section{Introduction}

Health economic issues are of growing importance in all health systems. Precise cost data are needed for decisions in health care and health policy making. Economic evaluations are necessary in order to make appropriate use of different treatment options. Cost-of-illness studies are a well-recognized tool to show the financial burden of diseases in a country and to identify subgroups for which the costs are particularly high.

Psoriasis is a skin disease which has substantial socioeconomic bearing for several reasons: (1) it is a highly prevalent disease, affecting about $2-3 \%$ of adults in Western populations [1-6]; (2) it is a chronic disease which is associated with permanent or frequently recurring, highly visible and symptomatic skin lesions [7, 8]; (3) it leads to significant burden of disease and a reduction in qual-

\section{KARGER}

Fax +41613061234 E-Mail karger@karger.ch www.karger.com
(C) 2006 S. Karger AG, Basel

$1018-8665 / 06 / 2122-0137 \$ 23.50 / 0$

Accessible online at: www.karger.com/drm 
ity of life (QoL) in patients from all countries [9-12]; (4) many patients with psoriasis are of working age, this results in work day loss, and therefore increased indirect costs (productivity losses).

In spite of the high socioeconomic significance of psoriasis in the Western world, only few studies have been published assessing the disease-related costs of psoriasis, most of them deriving form Anglo-American health systems [13-18]. Regardless of the specific health system, the cost-of-illness studies on psoriasis indicate considerable economic consequences [15] in countries such as Australia [16], the USA [17], the UK [18] and Italy [19]. As expected, the costs for psoriasis patients depend on disease severity, with higher costs in severe and relapsing cases [20].

In Germany, only data on costs of inpatient treatment of psoriasis are available; they were estimated at $€ 160$ million in 2001 [21]. These estimations are derived from statistical data of the German Statutory Health Insurance. However, there is still a lack of bottom-up data showing the cost of psoriasis in the general population, especially in relation to the quality of life reduction and to the severity of the disease. In order to gain such data, the present cost-of-illness study was performed including office- and hospital outpatient-based dermatologists focusing on the treatment of patients with moderate to severe plaque psoriasis in Germany.

\section{Design and Methods}

The study is a retrospective cost-of-illness study with a societal cost perspective. Costs were considered from two perspectives: the main analysis presents the societal perspective that includes all costs (direct medical, direct nonmedical and indirect), regardless of who pays for the resource. A second analysis presents costs from the public payers' perspective, including costs to the statutory health insurance funds, to the nursing care insurance and to invalidity pension plans (results will be presented in a further publication).

The objective of the study was to estimate all costs related to moderate to severe plaque psoriasis. Therefore only plaque-psoriasis-specific resource consumption was included.

An analysis considering the perspective of public payers as well as the QoL data will be presented in a further publication.

\section{Costs}

In this study, the indirect costs related to psoriasis were registered by the patients. They consist of periods of inability to work (sick leave), periods of unemployment, occupational retraining and early retirement. For an estimation of these costs, the German Recommendations for Health Economic Evaluations [22] suggest the use of the friction cost approach. This concept takes the employment situation into consideration and estimates a productivity loss not exceeding the mean time of an unfilled vacancy. The average duration of vacancies reported to the employment offices is the ap- proximate value for the mean friction period of all vacancies in the job market. On average, it takes 3 months to find a replacement for a patient or a pensioner. The productivity loss for 1 day off work was calculated as $€ 91.15$ per day using the following formula: Mean productivity loss $=$ gross income of employed persons/(total number of employees $\times 365$ days).

Direct costs were calculated in accordance with the current tariffs valid for the statutory health insurance in Germany. For inpatient costs, the individual hospital day rates were queried for the respective hospitals. The costs of pharmaceuticals were derived from the 2003 official drug index and from the price list for pharmacists for self-prepared prescriptions. Costs borne by the patient were calculated using the information given in the patient's questionnaire.

The total costs include the direct and indirect costs in addition to some smaller amounts for sickness allowances to be paid by sick funds for sick leaves exceeding 6 weeks and voluntary benefits paid by the sick funds, e.g. co-payment for a home solarium.

Sample

The study was performed at office-based dermatologists' and in dermatology outpatient departments in different regions in Germany between October 2003 and February 2004. The study centers were selected to provide a broad geographical distribution in order to ensure a representative documentation of the standard care of moderate to severe plaque psoriasis.

Assuming a response rate of $80 \%$, seventeen study centers were asked to enroll a total of 220 patients in order to get at least 180 evaluable patients. Eligible patients were identified by a review of the center's patient records. Enrollment into the study took place during the regular appointments when physicians consecutively addressed patients who met the inclusion and exclusion criteria. After giving their informed consent, the patients received several questionnaires related to disease severity information and to out-ofpocket expenses for psoriasis treatment in the previous 12 months as well as validated QoL questionnaires the same day. Patients were asked to fill out the questionnaires within a week and to send them to the study center in a stamped envelope. The conduct of the study did not require any additional appointments.

\section{Data Collection}

The data were collected by means of a multipart questionnaire, which contained:

(1) Physician's questionnaire: demographic data, assessment of the disease severity using the Psoriasis Area Severity Index (PASI) [23] and/or Psoriatic Body Surface Area (PBSA) [24] and Physicians Global Assessment (PGA) [25], out- and inpatient care, remedies and therapeutic interventions, rehabilitation, pharmaceuticals, inability to work and overall assessment of therapy. The disease severity parameters were assessed the same day the patient was enrolled into the study. The information regarding the resource consumption covered the previous 12 months and was extracted from the patient's record.

(2) Patient's questionnaires: information about the severity of the disease, daily time required for skin care, past therapies, private hospital and stationary treatment sessions ('cures'), co-payments for drugs and hospitalization, costs of applied measures and remedies, duration of illness and productivity losses. For the assessment of quality of life, German versions of the questionnaires 36Item Short-Form health survey (SF-36) [26, 27] and Dermatology Life Quality Index (DLQI) [28] were used. 
Table 1. Age, BMI and gender overall $(\mathrm{n}=184)$ and by patient subgroup

\begin{tabular}{lllll}
\hline Patients & $\begin{array}{l}\mathrm{A} \\
(\mathrm{n}=60)\end{array}$ & $\begin{array}{l}\mathrm{B} \\
(\mathrm{n}=63)\end{array}$ & $\begin{array}{l}\mathrm{C} \\
(\mathrm{n}=61)\end{array}$ & $\begin{array}{l}\text { Total } \\
(\mathrm{n}=184)\end{array}$ \\
\hline $\begin{array}{l}\text { Mean age, years } \\
\text { Mean BMI, kg/m } \mathrm{m}^{2}\end{array}$ & $52.8 \pm 13.1$ & $50.7 \pm 13.5$ & $51.7 \pm 12.9$ & $51.7 \pm 13.1$ \\
$\begin{array}{l}\text { Gender } \\
\quad \text { Male }\end{array}$ & $28.7 \pm 4.87$ & $28.3 \pm 6.82$ & $27.8 \pm 5.73$ & $28.3 \pm 5.84$ \\
$\quad$ Female & 35 & 49 & 38 & 122 \\
& 25 & 14 & 23 & 62 \\
\hline
\end{tabular}

\section{Inclusion Criteria}

Patients aged 18 years and more with moderate to severe plaque psoriasis defined as PASI score higher than 12 and/or a PBSA higher than $10 \%$ during the previous year were enrolled. All patient costs were covered by the statutory health insurance. A continuous surveillance by the center during the previous year and a detailed documentation of the patient's history were required.

The patients were stratified into 3 subgroups:

Subgroup A. Patients treated with other than systemic therapies.

Subgroup B. Patients treated with conventional systemic therapy e.g. methotrexate, cyclosporine, oral retinoids, PUVA/UVB, fumaric acid derivates.

Subgroup $C$. Patients not adequately controlled by conventional systemic therapies because they have failed to respond to, or had contraindications to, or were intolerant to at least 2 systemic therapies (high-need patients).

Each center was to select 4-7 patients per subgroup in order to attain an even distribution of patients within the groups. The subgroups were defined for a further differentiation of cost-of-illness and QoL data according to disease severity.

\section{Exclusion Criteria}

Patients undergoing clinical trials during the past year and patients covered by a private health insurance were excluded.

\section{Results}

\section{Patients}

One hundred eighty-four patients were enrolled in the study by 6 office-based dermatologists and 8 dermatology outpatient departments. All but one patient returned the patient questionnaire. Furthermore, 2 DLQI and 6 SF-36 questionnaires were not sent back. Sixty patients were enrolled in subgroup A, 63 in subgroup B and 61 in subgroup C.

The mean age was 51.7 years (SD 13.1). The ages of the youngest and oldest study participants were 21 and 83 years, respectively. The mean body mass index (BMI) was $28.3 \mathrm{~kg} / \mathrm{m}^{2}$ (SD 5.84) with a minimum of 16.9 and a maximum of $59.3 \mathrm{~kg} / \mathrm{m}^{2}$. One hundred twenty-two patients $(66.3 \%)$ were males and 62 were females. Further
Table 2. PASI and PBSA overall $(n=184)$ and by patient subgroup

\begin{tabular}{lrr}
\hline Patient subgroup & PASI & PBSA \% \\
\hline Group A: no systemic treatment & & \\
Mean & 19.3 & 30.9 \\
SD & 7.8 & 15.3 \\
Minimum & 8.8 & 8.5 \\
Maximum & 54.1 & 95.0 \\
Group B: systemic treatment & & \\
Mean & 13.5 & 21.2 \\
SD & 11.2 & 14.9 \\
Minimum & 0.3 & 3.0 \\
Maximum & 53.0 & 64.0 \\
Group C: high-need patients & & \\
Mean & 22.2 & 34.9 \\
SD & 12.2 & 19.5 \\
Minimum & 1.8 & 1.5 \\
Maximum & 58.2 & 85.5 \\
\hline Total & & \\
Mean & 18.2 & 28.9 \\
SD & 11.1 & 17.6 \\
Minimum & 0.3 & 1.5 \\
Maximum & 58.2 & 95.0 \\
& &
\end{tabular}

details on the patients' characteristics overall and per subgroup are shown in table 1 .

\section{Severity and Classification}

Overall, the patients showed a mean PASI of 18.2 and a PBSA of $28.9 \%$. The most severe cases were found in subgroup $\mathrm{C}$ which included high-need patients with a mean PASI of 22.2 and a PBSA of $34.9 \%$ (table 2), followed by subgroup A patients under treatment with nonsystemic therapies (PASI 19.3; PBSA 30.9\%). The patients in subgroup B under systemic therapy showed the least severe disease (PASI 13.5, PBSA 21.2\%).

The mean duration of disease was 21.8 years with a minimum of 1 and a maximum of 66 years. More than 
Table 3. Outpatient costs overall $(n=184)$ and by patient subgroup in euros per year

\begin{tabular}{lccccc}
\hline Patient subgroup & $\mathrm{n}$ & Mean & SD & Minimum & Maximum \\
\hline Group A: no systemic treatment & 60 & 188 & 103 & 0.00 & 409 \\
Group B: systemic treatment & 63 & 224 & 118 & 45 & 677 \\
Group C: high-need patients & 61 & 199 & 139 & 0.00 & 769 \\
\hline Total & 184 & 204 & 121 & 0.00 & 769 \\
\hline
\end{tabular}

\begin{tabular}{lrrrrr}
\hline Patient subgroup & $\mathrm{n}$ & Mean & SD & Minimum & Maximum \\
\hline Group A: no systemic treatment & 60 & 1,187 & 3,045 & 0.00 & 17,299 \\
Group B: systemic treatment & 63 & 1,822 & 4,274 & 0.00 & 21,475 \\
Group C: high-need patients & 61 & 3,887 & 7,453 & 0.00 & 32,991 \\
\hline Total & 184 & 2,299 & 5,359 & 0.00 & 32,991 \\
\hline
\end{tabular}

Table 4. Inpatient costs overall $(n=184)$ and by patient subgroup in euros per year half of the patients had already suffered from psoriasis longer than $40 \%$ of their lifetime.

Regarding the daily time for psoriasis care, only 6 (3.3\%) patients indicated a time less than $10 \mathrm{~min}$. The average time was 57.5 (SD 47.2) min per day with a minimum of 1 and a maximum of 360 min varying from $50.5 \mathrm{~min}$ in subgroup B to $56.8 \mathrm{~min}$ in subgroup A and $65.5 \mathrm{~min}$ in subgroup $\mathrm{C}$.

\section{Socioeconomic Findings}

One hundred eighty-one patients answered the question related to their employment situation. 56.4\% (n = $102 / 181$ ) were employed during the 12-month observation period while $43.6 \%(n=79 / 181)$ were not employed (e.g. housewives, retired, jobless). In total $19.0 \%(n=15)$ of the patients not employed $(n=79)$ were out of work, 6 of them due to psoriasis. Further data showed that $3.9 \%(n=7)$ of the patients had had to change their job because of their illness. Two among them had been retrained for a different occupation. $24.3 \%(n=44 / 181)$ of patients had a 'reduction in earning capacity' (specific German statutory status) due to psoriasis. The mean degree of the 'reduction in earning capacity' among these patients was $51.8 \%$ (SD 22.2). $4.4 \%(\mathrm{n}=8 / 181)$ had gone into early retirement at an age between 40 and 62 years because of psoriasis.

\section{Costs}

Analysis of outpatient treatment revealed that most patients $(73.1 \%)$ were treated primarily at one physician office or one outpatient clinic. Merely 26.9\% were treated by more than one physician. As expected, the resource consumption for outpatient care was relatively low com- pared to other health care costs. Overall, the mean annual outpatient costs were $€ 204$ with $€ 188$ for subgroup A, $€ 224$ for subgroup B and $€ 199$ for subgroup C (table 3 ). The expenses were mainly incurred for consultation, phototherapy and laboratory tests.

Fifty-two patients $(28.3 \%)$ were hospitalized due to their plaque psoriasis. A total of 63 admissions were documented (42 patients: 1 stay, 9 patients: 2 stays, 1 patient: 3 stays). The mean length of stay for all admissions ( $\mathrm{n}=$ 63) was 29.8 days. The number of hospital days per patient and per year was 39.1 days on average. Patients of subgroup $\mathrm{C}(\mathrm{n}=24)$ showed the highest number of hospital days per year with a mean of 49.4 days followed by patients of subgroup B $(n=15)$ with 33.5 days and patients of subgroup A $(n=13)$ with 26.8 days.

The total costs for the stationary sector were calculated by summing up the expenses of rehabilitation, cures and hospital stays paid by the sick funds or the pension insurance institution. On average, costs of $€ 2,299$ per year were incurred for inpatient treatment.

High-need patients (subgroup C) showed the highest costs with $€ 3,887$ followed by patients under conventional systemic therapy (subgroup B) with $€ 1,822$ and patients with nonsystemic therapy (subgroup A) with $€ 1,187$ per year (table 4 ).

The annual medication costs related to the treatment of plaque psoriasis were calculated using the physicians' questionnaire. The average medication costs were $€ 2,014$ in the whole study group. Subgroup B had the highest annual costs with a mean of $€ 3,089$ followed by subgroup $C$ (high-need patients) with $€ 1,860$ (table 5). The lower medication costs for subgroup $\mathrm{C}$ are a consequence of lacking 


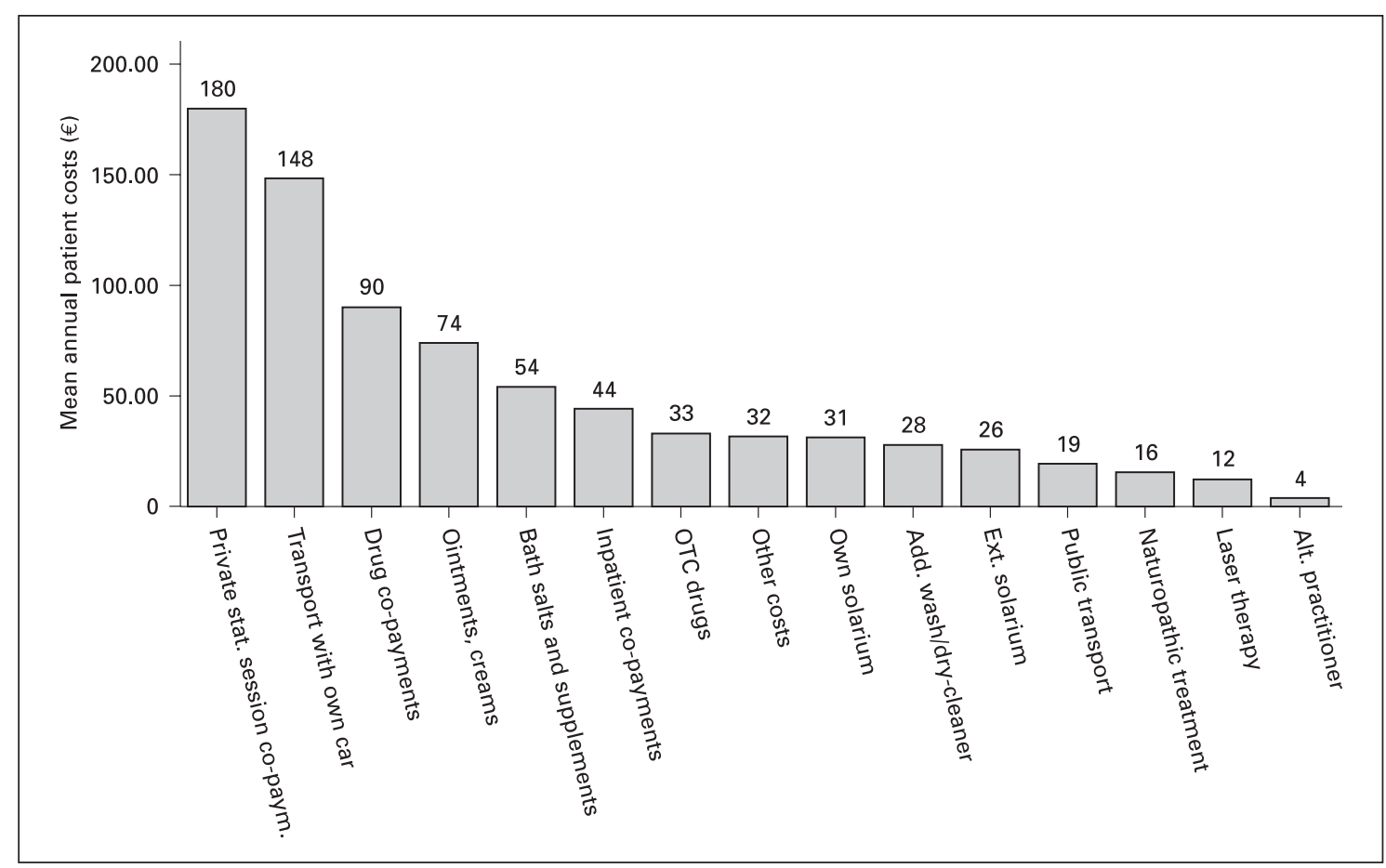

Fig. 1. Patient expenses and co-payments in euros per year.

Table 5. Medication costs overall $(n=184)$ and by patient subgroup in euros per year

\begin{tabular}{lrrrrr}
\hline Patient subgroup & $\mathrm{n}$ & Mean & SD & Minimum & Maximum \\
\hline Group A: no systemic treatment & 60 & 1,042 & 1,548 & 0.00 & 7,779 \\
Group B: systemic treatment & 63 & 3,089 & 3,980 & 10.84 & 28,022 \\
Group C: high-need patients & 61 & 1,860 & 2,315 & 0.00 & 10,647 \\
\hline Total & 184 & 2,014 & 2,935 & 0.00 & 28,022 \\
\hline
\end{tabular}

therapeutic alternatives with effective drugs and correspond to the high costs for inpatient care. Subgroup A had average medication costs of $€ 1,042$ per year. On average 4.7 different drugs per patient and year were used.

The mean annual direct costs borne by the patients including co-payments, measures like private cures, solarium, naturopathic treatment, additional payments or travel costs (fig. 1) resulted in $€ 794$ overall, varying from $€ 609$ for subgroup A to $€ 770$ for subgroup $B$ and $€ 1,002$ for subgroup C (fig. 2).

Moderate to severe psoriasis resulted in a mean annual productivity loss of $€ 1,310$. Productivity loss ranged from $€ 1,048$ in subgroup A to $€ 1,635$ in subgroup C. The mean annual productivity loss for patients of subgroup B amounted to $€ 1,244$ (table 6).
A total of 57 patients $(31.0 \%)$ reported inactive periods due to sick leave because of their psoriasis. On average, the duration of absence in this group was 46.4 days with a minimum of 1 and a maximum of 90 days (maximum limit in accordance with the friction cost approach). The number of days they did not work due to psoriasis rose with increasing PASI (Pearson correlation coefficient: 0.374 ; significance level 0.01 ) and was on average between 10 days for a PASI of 12 and 29 days for a PASI of 50. Overall, the mean number of sick leave days was 14.1 days, corresponding with the results of previously published studies [11].

Adding direct and indirect costs resulted in the total costs from the societal perspective. The total sum includes all presented cost factors in addition to some small- 


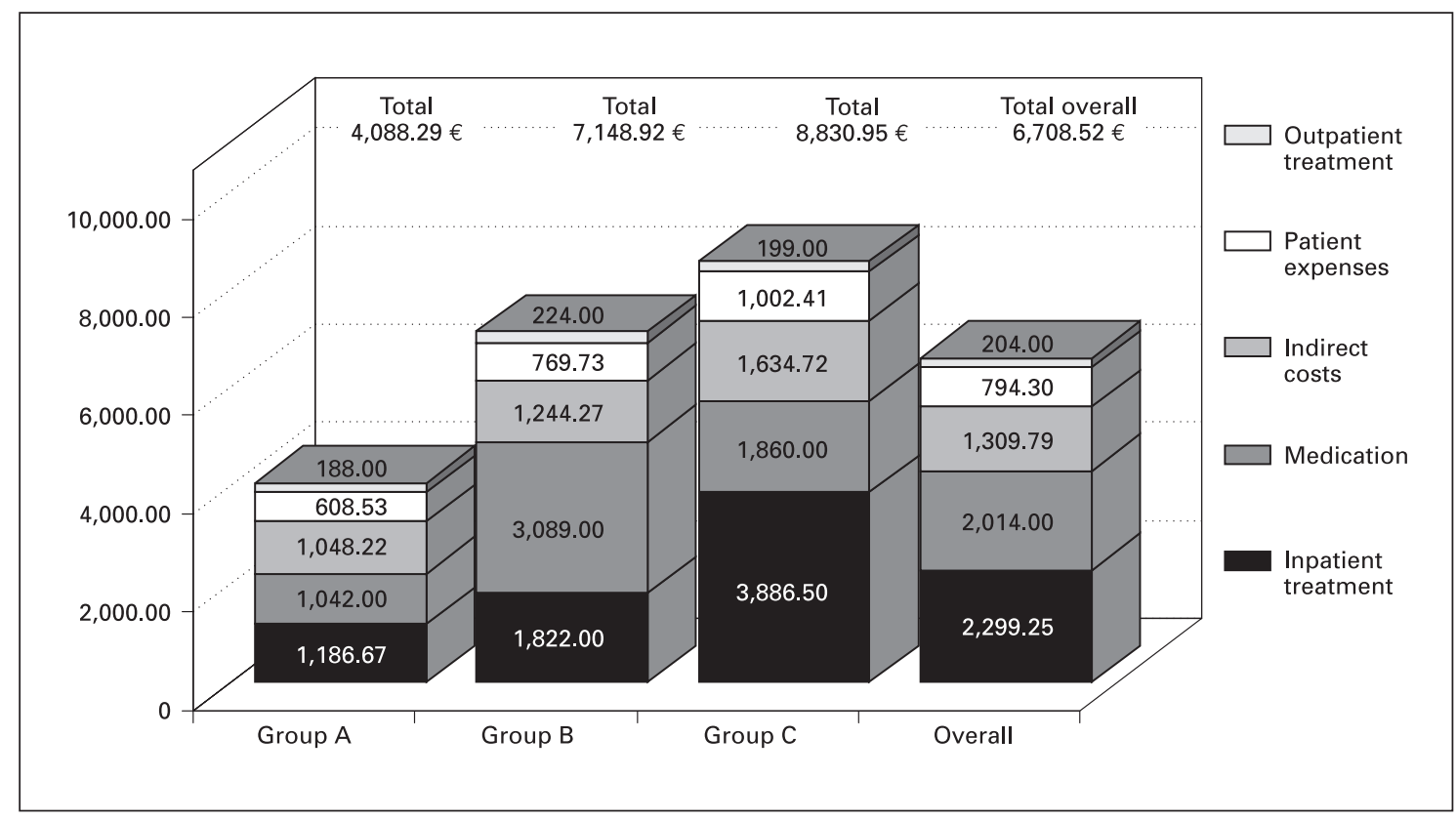

Fig. 2. Distribution of costs over health care sectors overall $(n=184)$ and by patient subgroup in euros per year.

Table 6. Indirect costs overall $(n=184)$ and by patient subgroup in euros per year
Table 7. Total costs overall $(n=184)$ and by patient subgroup in euros per year (societal perspective)

\begin{tabular}{lrrrrr}
\hline Patient subgroup & $\mathrm{n}$ & Mean & SD & Minimum & Maximum \\
\hline Group A: no systemic treatment & 60 & 1,048 & 2,312 & 0.00 & 8,204 \\
Group B: systemic treatment & 63 & 1,244 & 2,507 & 0.00 & 8,204 \\
Group C: high-need patients & 61 & 1,635 & 2,895 & 0.00 & 8,204 \\
\hline Total & 184 & 1,310 & 2,581 & 0.00 & 8,204 \\
\hline
\end{tabular}

${ }^{1}$ The upper limit for the maximum direct costs results from the friction costs approach (maximum work loss: 3 months).

\begin{tabular}{lccrcc}
\hline Patient subgroup & $\mathrm{n}$ & Mean & SD & Minimum & Maximum \\
\hline Group A: no systemic treatment & 60 & 4,088 & 4,776 & 243 & 25,446 \\
Group B: systemic treatment & 63 & 7,149 & 7,626 & 282 & 33,743 \\
Group C: high-need patients & 61 & 8,831 & 10,069 & 395 & 53,599 \\
\hline Total & 184 & 6,709 & 8,007 & 243 & 53,599 \\
\hline
\end{tabular}

er components (sickness allowances, voluntary cost coverage). Clear differences between the subgroups can be seen (table 7).

Overall, the mean annual total costs amounted to $€ 6,709$. The costs for high-need patients (subgroup C) were highest with $€ 8,831$, while patients under conven- tional systemic therapy (subgroup B) had a mean of $€ 7,149$ and those under treatment but without systemic therapy incurred costs of $€ 4,088$ (table 7). A detailed overview over the cost structure per subgroup is shown in figure 2. 


\section{Discussion}

The aim of this study was to assess the cost of illness of patients with moderate to severe plaque psoriasis from a societal perspective using the friction cost approach in Germany. Approximately $25 \%$ of all psoriasis patients experience a moderate to severe form of the disease requiring systemic treatment to control their disease adequately [29]. The study was conducted before the advent of the new biologic agents [30] when the most frequently administered systemic therapies for these patients were cyclosporine, methotrexate, fumaric acid derivates and PUVA. Because of their toxicity, the use of these drugs is limited. Moreover there is a significant group of patients for whom there are no effective treatment options due to inefficacy, poor tolerability or contraindications to conventional systemic drugs [31]. This led to heterogeneous treatment schemes e.g. systemic treatments, topical treatments and treatments for high-need patients with ineffective rotating, sequencing or combining of therapies. These nonstandardized treatment approaches have a varying economic impact on the relevant cost domains. The current study therefore analyzed the costs of patients with moderate to severe plaque psoriasis according to treatment schemes tailored to the specific patient's requirements and showed their implication for the different cost domains. Since only few data about the economic consequences of psoriasis in Germany are available, this study may help to clarify its financial impact. It is important to consider the impact of the costs on the whole society because psoriasis is a chronic and therefore a lifelong disease which manifests at an age at which people work and therefore societal costs such as productivity losses must be considered.

The data presented here show that moderate to severe plaque psoriasis imposes a considerable economic burden on societies, public payers and on the individuals themselves with total costs ranging from $€ 4,088$ to $€ 8,831$ (fig. 2). In particular the social insurance systems are burdened with high direct costs of psoriasis caused by in- and outpatient care, medication and rehabilitation (about 2/3 of the overall costs) that are paid in Germany by the statutory health and pension insurances.

One of the important outcomes of this study was the finding that high-need patients with moderate to severe plaque psoriasis produced the highest total costs whereas they showed the highest disease activity. The main costs generated by these patients were for hospitalization for a high number of days per year. Thereby these patients also had considerable productivity losses caused by sick leaves. Nevertheless, the outpatient treatment of these patients produced notable expenses for drugs with costs of $€ 1,860$. In addition to this impact for the whole society, the disease imposed a high financial burden on the patients themselves with $€ 794$ out-of-pocket expenses and a time-consuming daily personal care with an average time of $65.5 \mathrm{~min}$.

As one would expect the costs for the medical treatment for patients treated with conventional systemic therapy were the highest. Despite systemic treatment, it was noticeable that these patients still had a mean PASI of 13.5 and PBSA of $21.2 \%$. Altogether, the patients of subgroup B produced high total costs with $€ 7,149$ not only caused by medication but also by considerable costs for inpatient care with $€ 1,822$ and high out-of-pocket expenses for the patients themselves with $€ 770$.

Patients of subgroup A reported lower treatment and indirect costs in comparison with the other patient subgroups but nevertheless notable out-of-pocket expenses with $€ 609$ and moreover they had a high PASI (19.3) and PBSA (30.9\%).

The data showed that analyzing the different treatment schemes gives more information about the economic impact related to the treatment requirements of patients. However, comparing all cost domains, it was obvious that inpatient treatment and medication are the most relevant expense factors in the conventional treatment of moderate to severe plaque psoriasis.

Although the costs of conventional treatment options are high, the patient-reported outcome is still unsatisfactory $[32,33]$. In particular the treatment of high-need patients requires more attention. An improvement of this situation from the medical as well as from the economic point of view seems imperative.

Future studies should focus on how to improve the medical care of moderate to severe psoriasis in Germany from the patients' and society's perspective. This would include a better understanding of the cost-effectiveness ratios of relevant psoriasis treatments as well as of costutility ratios in terms of patients' QoL.

\section{Participants}

Prof. Dr. J.C. Prinz, Department of Dermatology, Ludwig Maximilian University Hospital, Munich, Prof. Dr. M. Augustin, Department of Dermatology, University Hospital, Freiburg, Prof. Dr. W. Sterry/Dr. M. Friedrich, Department of Dermatology, University Hospital Charité, Berlin, Prof. Dr. P. Altmeyer/Dr. A. Bader, St. Josef Hospital, Bochum, Prof. Dr. K. Reich, Department of Dermatology, University Hospital, Göttingen, Prof. Dr. R. Schopf, 
Department of Dermatology, University Hospital, Mainz, Dr. D. Thaci, Department of Dermatology, University Hospital, Frankfurt, Dr. U. Jappe, Department of Dermatology, University Hospital, Heidelberg, Prof. Dr. J. Barth, Borna, Dr. T. Dirschka, Wuppertal, Dr. K. Fritz, Landau, Drs. H. Scholz/M. Sebastian, Mahlow, Dr. E. Schubert, Würzburg, Dr. M. Hornstein, Düsseldorf.

\section{Acknowledgement}

The study was funded by Serono GmbH, Unterschleissheim, Germany.

\section{References}

1 Lewis VJ, Finlay AY: Two decades experience of the Psoriasis Disability Index. Dermatology 2005;210:261-268.

2 Uhoda E, Lévêque J-L, Piérard GE: Silicon image sensor technology for in vivo detection of surfactant-induced corneocyte swelling and drying. Dermatology 2005;210:184-188.

3 Augustin M, Wenninger K, Amon U, Schroth MJ, Küster W, Chren M, Kupfer J, Gieler U: German adaptation of the Skindex-29 Questionnaire on quality of life in dermatology: validation and clinical results. Dermatology 2004; 209:14-20.

4 Naldi L: Epidemiology of psoriasis. Curr Drug Targets Inflamm Allergy 2004;3:121-128.

5 Nevitt GJ, Hutchinson PE: Psoriasis in the community: prevalence, severity and patients' beliefs and attitudes towards the disease. Br J Dermatol 1996;135:533-537.

6 Griffiths CEM, Clark CM, Chalmers RJG, A Li Wan Po, Williams HC: A systematic review of treatments for severe psoriasis. Health Technol Assess 2000; 4(40).

7 Farber EM, Nall ML: The natural history of psoriasis in 5,600 patients. Dermatologica 1974; 148:1-18.

8 Koo J, Lebwohl M: Duration of remission of psoriasis therapies. J Am Acad Dermatol 1999; 41:51-59.

9 Lundberg L, Johannesson M, Silverdahl M, et al: Quality of life, health-state utilities and willingness to pay in patients with psoriasis and atopic eczema. Br J Dermatol 1999; 141:1067_ 1075.

10 Krueger G, Koo J, Lebwohl M, Menter A: The impact of psoriasis on quality of life: results of a 1998 National Psoriasis Foundation patientmembership survey. Arch Dermatol 2001;137: 280-284.

11 Finlay AY, Coles EC: The effect of severe psoriasis on the quality of life of 369 patients. $\mathrm{Br}$ J Dermatol 1995;132:236-244.
12 Augustin M, Zschocke I, Seidenglanz K, Lange S, Schiffler A, Amon U: Validation and clinical results of the FLQA-d, a quality of life questionnaire for patients with chronic skin diseases. Dermatol Psychosom 2000;1:12-17.

13 Sander HM, Morris LF, Phillips CM, Harrison PE, Menter A: The annual cost of psoriasis. J Am Acad Dermatol 1993;28:422-425.

14 Lee GC, Weinstein GD: Comparative cost-effectiveness of different treatments for psoriasis; in Rajagopalan R, Sherer EF (eds): Care Management of Skin Diseases. New York, Dekker, 1998

15 Galadari I, Rigel E, Lebwohl M: The cost of psoriasis treatment. J Eur Acad Dermatol Venereol 2001;15:290-291.

16 Jenner N, Campbell J, Plunkett A, et al: Cost of psoriasis: a study on the morbidity and financial effects of having psoriasis in Australia. Austral J Dermatol 2002;43:255-261.

17 Javitz HS, Ward MM, Farber E, et al: The direct cost of care for psoriasis and psoriatic arthritis in the United States. J Am Acad Dermatol 2002; 46:850-860.

18 Poyner TF, Wall ARJ, Adnitt PI: Economic impact of psoriasis treatment on the patient and on the national health service. J Dermatol Treat 1999; 10:25-29.

19 Finzi AF, Mantovani LG, Belisari A, et al: The cost of hospital-related care of patients with psoriasis in Italy based on the AISP study. J Eur Acad Dermatol Venereol. 2001;15:320324.

20 Feldmann SR, Fleischer AB Jr, Reboussin $\mathrm{DM}$, et al: The economic impact of psoriasis increases with psoriasis severity. J Am Acad Dermatol 1997;37:564-569.

21 Traupe H, Robra B: Gesundheitsberichterstattung des Bundes. Psoriasis. Robert-Koch-Institut Berlin, 2002, No 11.

22 Hannoveraner Konsens Gruppe: Deutsche Empfehlungen zur gesundheitsökonomischen Evaluation. Revidierte Fassung des Hannoveraner Konsens. Med Klin 2000;95:52-55.
23 Fredriksson T, Pettersson U: Severe psoriasis - Oral therapy with a new retinoid. Dermatologica 1978; 157:238-244.

24 Krüger GG, Feldman SR, Camisa C, et al: Two considerations for patients with psoriasis and their clinicians: what defines mild, moderate and severe psoriasis? What constitutes a clinically significant improvement when treating psoriasis? J Am Acad Dermatol 2000;43(2 pt 1):281-285

25 Richard G, Langley MD, Charles N, Ellis MD Evaluating psoriasis with Psoriasis Area and Severity Index, Psoriasis Global Assessment and Lattice System Physician's Global Assessment. J Am Acad Dermatol 2004;51:563569.

26 Ware JE, Donald Shebourne C: The MOS 36 item short-form health survey (SF-36). I. Conceptual framework and item selection. Med Care 1992;30:473-483.

27 Bullinger M, Kirchberger I: Der SF-36 Fragebogen zum Gesundheitszustand. Handbuch für die deutschsprachige Fragebogenversion. Göttingen, Hogrefe Verlag, 1998.

28 Finlay AY, Kahn GK: Dermatology Life Quality Index (DLQI): a simple practical measure for routine clinical use. Clin Exp Dermatol 1994;9:210-216.

29 Boehnke WH: Immunmodulatory drugs for psoriasis. Br Med J 2003;327:634-635.

30 Naldi L: A new era in the management of psoriasis? Promises and facts. Dermatology 2005; 210:179-181.

31 Sterry W, et al: Biological therapies in the systemic management of psoriasis: International consensus conference. Br J Dermatol 2004; 151(S69):3-17.

32 All Party Parliamentary Group on Skin: Report on the enquiry into the impact of skin diseases on people's lives, July, 2003.

33 Salonen S-H: The EUROPSO Psoriasis Patient Survey: treatment history and satisfaction. Eur Acad Dermatol Venereol Int Spring Symp, 2003, p 60. 